\title{
Tratamentos integrados em efluente metal-mecânico: precipitação química e biotratamento em reator do tipo air-lift
}

\section{Integrated treatments for metalworking effluent: chemistry precipitation and biotreatment in air-lift reactor type}

\author{
Daniel Delgado Queissada \\ Biólogo pela Universidade Federal de Alagoas (Ufal); Doutor em Biotecnologia Industrial pela Universidade de São Paulo (USP).
}

Flávio Teixeira da Silva

Químico pela Universidade Estadual de Campinas (Unicamp); Doutor em Química pela Unicamp.

Teresa Cristina Brazil de Paiva

Engenheira de Alimentos pela Universidade Federal da Paraíba (UFPB); Doutora em Ciências pela Unicamp.

\section{Resumo}

Os objetivos deste trabalho foram: realizar a caracterização físico-química de um efluente metal-mecânico e efetuar o tratamento integrado (precipitação química e biotratamento), utilizando micro-organismos autóctones do efluente (FI e FV) e uma referência (A. niger). A caracterização indicou pH de 1,7; cor de $1.495 \mathrm{mg} \mathrm{Pt.L-1}$; demanda química de oxigênio de $9.147 \mathrm{mgO}_{2} \mathrm{~L}^{-1} ; 887 \mathrm{mg} \cdot \mathrm{L}^{-1}$ de óleo e graxa, além de $2,5 \mathrm{mgO}_{2} \cdot \mathrm{L}^{-1}$ de oxigênio dissolvido. Com o tratamento por precipitação química, obteve-se, em $\mathrm{pH}=7,5$, a redução de todos os íons metálicos investigados. Após o biotratamento, a cor foi reduzida em 95\%, utilizando o micro-organismos FV. As reduções da demanda química de oxigênio e de óleo e graxa foram mais significativas utilizando Fl, que reduziu os mesmos em 52 e 62\%, respectivamente. Estes resultados indicaram que os micro-organismos autóctones do efluente foram mais eficazes no tratamento do mesmo do que o organismo de referência A. niger.

Palavras-chave: precipitação química; reator tipo air-lift; efluente metal-mecânico.

\section{Abstract}

The objectives of this paper were: to perform the physical-chemical characterization of a metalworking effluent and to carry out the integrated treatment (chemical precipitation and biotreatment), using effluent autochthonous microorganisms ( $\mathrm{Fl}$ and FV) and a reference (A. niger). The characterization indicated

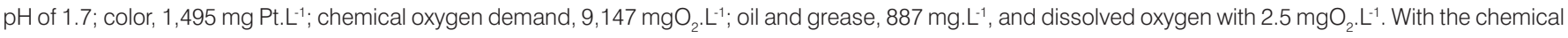
precipitation treatment, in $\mathrm{pH}=7.5$, the reduction of all the investigated metallic ions was obtained. The color was reduced $95 \%$ after the biotreatment using the FV microorganism. The chemical oxygen demand and oil and grease reductions were more significant when using $\mathrm{Fl}$, which reduced the same in 52 and $62 \%$, respectively. These results indicated that the autochthonous microorganisms were more efficient in the effluent treatment than the reference organism $A$. niger. Keywords: chemical precipitation; air-lift reactor type; metalworking effluent. 


\section{Introdução}

Os fluidos de corte são amplamente utilizados como refrigerantes e lubrificantes durante os processos de usinagem. O uso anual mundial é estimado em $2.10^{9}$ litros e o seu desperdício pode ultrapassar dez vezes esta proporção, já que esses são diluídos antes do uso (CHENG; PHIPPS; ALKHADDAR, 2005).

A complexidade e variedade da constituição dos efluentes metaismecânicos criaram dificuldades imensas para o tratamento adequado do mesmo, por isso a busca de novos tratamentos e alternativas para os tratamentos já existentes é imprescindível. Geralmente, estes efluentes são tipicamente tratados com processos físico-químicos (VAN DER GAST; THOMPSON, 2004). Muitas vezes, estes tratamentos não são suficientes para remover todos os poluentes existentes nesses efluentes. Com isso, muitos compostos como bactericidas e outros xenobióticos, podem ser descartados em corpos d'água ou na rede de tratamento de esgoto, causando sérios problemas à vida aquática desses corpos receptores. O principal problema que este tipo de efluente pode causar ao ser descartado de forma inadequada na rede coletora de esgoto é a morte de vários microorganismos presentes no sistema de tratamento biológico dessas companhias (BIOWISE, 2000).

Geralmente, os efluentes da indústria metal-mecânica possuem altas concentrações de metais dissolvidos (LEMOS; SANTOS, 2007). Diversas técnicas podem ser utilizadas para retirar metais de efluentes, tornando os mesmos adequados para o lançamento em cursos d'água (PEREIRA NETO et al., 2008). O tratamento mais utilizado para a remoção de íons metálicos (IM) em efluentes da indústria metal-mecânica é a precipitação química, pois trata-se de um método de baixo custo e fácil execução (KURNIAWAN et al., 2006; MATLOCK et al., 2002; ZHOU et al., 1999).

Os sistemas de tratamentos de efluentes industriais, em sua maioria, são constituídos de processos físico-químicos seguidos de tratamentos biológicos. Essa integração de processos, geralmente, aperfeiçoa o sistema de tratamento de forma geral. Porém, para isso, é importante o uso de micro-organismos que não sofram nenhum tipo de inibição em relação aos poluentes encontrados no efluente. A maioria dos processos de usinagem é realizada utilizando os fluidos de corte como emulsões (proporções de fluido de corte e água, de acordo com a necessidade do processo). A adição de água nos fluidos de corte torna este ambiente favorável ao desenvolvimento de alguns microorganismos. Estes, por sua vez, são resistentes aos poluentes existentes nessas emulsões (ROSSMOORE, 1993). Com isso, tratamentos biológicos com microorganismos autóctones desses efluentes se tornam uma alternativa promissora para o tratamento dos mesmos.

A bioaumentação é um sistema de tratamento biológico que vem adquirindo muito espaço entre os processos de tratamento de efluentes industriais. Isso se deve ao fato de que este tipo de tratamento ocorre com microorganismos autóctones do próprio efluente, os mesmos conseguem se desenvolver e multiplicar sem nenhuma inibição, pois já estão adaptados aos poluentes existentes no efluente (VAN DER GAST et al., 2002).

Diante do exposto, os objetivos deste trabalho foram realizar a caracterização físico-química de um efluente contendo fluido de corte e efetuar o tratamento integrado com precipitação química e biotratamento em reator do tipo air-lift, utilizando dois microorganismos autóctones do efluente (FI e FV) e um de referência (A. niger).

\section{Metodologia}

\section{Efluente utilizado}

O efluente utilizado foi proveniente da etapa de desemulsificação por acidificação do sistema de tratamento realizado por uma indústria metal-mecânica, da região do Vale do Paraíba, em São Paulo. Esta etapa de desemulsificação foi realizada pela indústria para a remoção do excesso de óleo no efluente. Após a desemulsificação, a parte aquosa do efluente foi coletada de forma que o volume de amostragem retirado para o estudo fosse representativo do total. $\mathrm{O}$ volume total de amostra coletada foi de $40 \mathrm{~L}$ (dividido em dois frascos de 20 L). O volume de amostragem foi desmembrado em alíquotas de $40 \mathrm{~mL} ; 600 \mathrm{~mL} ; 1,5 \mathrm{~L}$ e 3,5 L, armazenados em recipientes plásticos e estocados em uma câmara fria à $-18^{\circ} \mathrm{C}$.

\section{Caracterização físico-química do efluente oleoso}

\section{Determinação de pH}

$\mathrm{O}$ pH da amostra do efluente foi determinado por pHmetro Analion - PM608.

\section{Determinação de cor}

A cor foi determinada de acordo com metodologia padrão da CPPA (1975). Em todas as determinações, as amostras foram previamente centrifugadas por 15 minutos a $3.500 \mathrm{rpm}$ e o pH ajustado para 7,6 com tampão fosfato de 0,1 mol/L. A absorbância da solução no espectro visível foi determinada em $465 \mathrm{~nm}$ contra água destilada em espectrofotômetro UV/visível, U2000 Hitachi. Os valores de absorbância foram transformados em miligramas de platina por litro (mg Pt/L), de acordo com a Equação 1 .

Cor $=500 \mathrm{~A}_{2} / \mathrm{A}_{1}$

Equação 1

Onde:

$\mathrm{A}_{1}$ : absorbância de uma solução padrão de platina-cobalto de 500 $\mathrm{mg} \mathrm{Pt} / \mathrm{L}\left(\mathrm{A}_{465}=0,132\right)$;

$\mathrm{A}_{2}$ : absorbância do efluente, medida em $465 \mathrm{~nm}$. 


\section{Determinação da demanda química de oxigênio}

A determinação da demanda química de oxigênio (DQO) foi realizada de acordo com o método padrão APHA (1998). Em ampolas de vidro (volume de $20 \mathrm{~mL}$; diâmetro de $2,3 \mathrm{~cm}$ ), foram adicionados 2,5 mL de amostra, 1,5 mL de solução digestora (10,12 g/L de dicromato de potássio; 33,3 g/L de sulfato de mercúrio II; 0,167 L/L (v/v) de $\mathrm{H}_{2} \mathrm{SO}_{4}$ ) e 3,5 $\mathrm{Ml}$ de solução catalítica (5,5 g de $\mathrm{AgSO}_{4}$ por $\mathrm{kg}$ de $\mathrm{H}_{2} \mathrm{SO}_{4}$ p.a.). Em seguida, as ampolas foram seladas com bico de bunsen e acondicionadas em estufa a $150^{\circ} \mathrm{C}$ por duas horas. Após esfriar, com a amostra ainda na ampola selada, foi realizada leitura de absortividade no comprimento de onda de $600 \mathrm{~nm}$, em um espectrofotômetro U-2000 Hitachi adaptado. A concentração da demanda de $\mathrm{O}_{2}$ da amostra, em mg. $\mathrm{L}^{-1}$, foi obtida a partir de uma curva de calibração que utilizou biftalato de potássio como padrão.

\section{Determinação de óleos e graxas (OG)}

Empregou-se o método descrito por APHA (1998). Separou-se $50 \mathrm{~mL}$ de amostra, e ajustou-se o $\mathrm{pH}$ para 1,0. Em um funil, colocouse um disco de musseline e um de papel de filtro $n^{\circ} 40$. Em seguida, filtrou-se a amostra e, com auxílio de uma pinça, foram transferidos o disco de musseline e o papel de filtro para o cartucho de extração. Assim, o cartucho de extração foi acondicionado no extrator Soxhlet. A extração foi conduzida utilizando-se n-hexano como solvente por quatro horas a uma velocidade de 20 ciclos por hora, obtendo-se um total de 80 ciclos. Após este período, o balão foi seco em banhomaria à $70^{\circ} \mathrm{C}$ até a secura. Logo, o mesmo foi colocado por um tempo de uma hora em estufa a $\pm 103^{\circ} \mathrm{C}$ e 30 minutos em dessecador (esse mesmo procedimento foi realizado antes da extração e o balão foi pesado). Posteriormente, o balão foi pesado e, por gravimetria, determinou-se o teor de OG conforme a Equação 2.

$$
\text { OG }(\mathrm{mg} \cdot \mathrm{L}-1)=\frac{(\mathrm{M} 1-\mathrm{M} 2) \times 106}{\mathrm{~V}(\mathrm{~mL})}
$$

Onde:

$$
\begin{aligned}
& \mathrm{M}_{1}=\text { peso do balão com resíduo }(\mathrm{g}) ; \\
& \mathrm{M}_{2}=\text { peso do balão sem resíduo }(\mathrm{g}) .
\end{aligned}
$$

\section{Determinação de oxigênio dissolvido}

A determinação de oxigênio dissolvido (OD) no efluente foi realizada por oxímetro portátil Sppencer Scientific, modelo YK-22DO.

\section{Determinação de íons metálicos}

A determinação dos IM foi realizada segundo APHA (1998). A metodologia consistiu em se evaporar, até quase secura, $25 \mathrm{~mL}$ de amostra. Em seguida, foram acrescentados $4 \mathrm{~mL}$ de $\mathrm{H}_{2} \mathrm{SO}_{4}$ concentrado e realizou-se a digestão até queima total de óleos e gorduras existentes. Posteriormente, foram adicionados lentamente $4 \mathrm{~mL}$ de $\mathrm{H}_{2} \mathrm{O}_{2}$ e $0,5 \mathrm{~mL}$ de $\mathrm{HCl}$. As amostras foram avolumadas para $25 \mathrm{~mL}$.
Para análise de mercúrio $(\mathrm{Hg})$, foi realizada a extração da amostra sem digestão com ditizona solubilizada em clorofórmio. As amostras foram determinadas por espectrometria de absorção atômica.

\section{Tratamento por precipitação química}

O tratamento por precipitação química teve como principal objetivo a remoção de IM presentes na amostra do efluente. Porém, após a retirada destes, também foram realizadas as determinações dos mesmos parâmetros da caracterização do efluente original para obeservar as possíveis reduções dos mesmos. Os ensaios de precipitação química foram realizados utilizando hidróxido de sódio $(\mathrm{NaOH})$, em pérolas e solução saturada, como agente precipitante. Em um béquer de $1 \mathrm{~L}$, foram colocados $400 \mathrm{~mL}$ de efluente, em temperatura ambiente, o qual foi agitado magneticamente. A agitação variou de 1.800 a $2.100 \mathrm{rpm}$, a agitação foi alta, pois a utilização de $\mathrm{NaOH}$ em pérolas dificultou a mesma. Um pHmetro foi colocado no recipiente para a medição de pH em tempo real. Em agitação, $\mathrm{NaOH}$ foi adicionado lentamente, ajustando o pH de 1,7 para 6,$5 ; 7,5 ; 8,5 ; 9,5 ; 10,5$ e 11,5. Após a estabilização do sistema, em cada valor de $\mathrm{pH}$, uma amostra de $30 \mathrm{~mL}$ foi coletada e deixada em repouso por três horas para total sedimentação dos IM, e, em seguida, foi retirada a fase aquosa para a determinação dos metais presentes nessa.

\section{Biotratamento em reator do tipo air-lift}

Os tratamentos foram realizados com os microorganismos FI e FV (autóctones do efluente), e com o fungo Aspergillus niger, que foi utilizado como micro-organismo padrão. Para isso, estes foram repicados para tubos contendo BDA (batata - dextrose - ágar) e incubados por 120 horas no escuro a $28^{\circ} \mathrm{C}$. Após esse período, a cultura sofreu uma suspensão em água destilada e autoclavada. Em seguida, as células foram quantificadas em Câmara de Neubauer, padronizando um volume contendo $10^{8}$ esporos. Cada alíquota da suspensão foi adicionada em reator do tipo air-lift, contendo $350 \mathrm{~mL}$ de efluente bruto, em triplicata e com pH 6,5. O tratamento ocorreu durante sete dias a $28^{\circ} \mathrm{C}$. Após o tratamento, o efluente foi deixado em repouso por 24 horas, e a fase aquosa coletada para a determinação dos parâmetros pós-tratamento. Na Figura 1 está esquematizado o reator que foi utilizado neste experimento.

\section{Resultados e discussão}

\section{Caracterização físico-química do efluente}

Os resultados relativos às determinações dos parâmetros utilizados para a caracterização físico-química do efluente são apresentados na Tabela 1.

Os resultados indicaram se tratar de um efluente com potencial altamente poluidor, devido à sua elevada acidez $(\mathrm{pH}=1,7 \pm 0,1)$ e coloração (1.495 $\pm 149 \mathrm{mg}$ Pt. $\left.\mathrm{L}^{-1}\right)$. A alta acidez está associada à etapa 


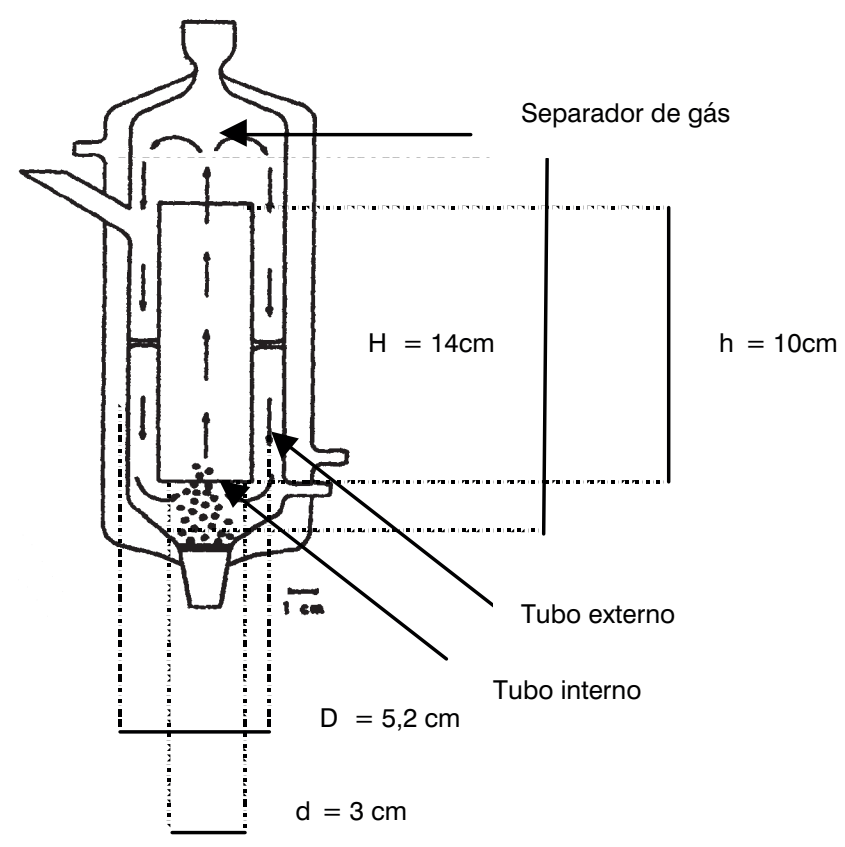

Figura 1 - Esquema do biorreator air-lift.

Tabela 1 - Características físico-químicas da amostra do efluente sem tratamento

\begin{tabular}{|c|c|c|}
\hline Parâmetros & Resultados & Padrão*** \\
\hline Temperatura & $25 \mathrm{C}$ & $<40^{\circ} \mathrm{C}$ \\
\hline $\mathrm{pH}$ & $1,7 \pm 0,1$ * & $5-9$ \\
\hline Cor (mg Pt. $\mathrm{L}^{-1}$ ) & $1495 \pm 149$ * & 75 \\
\hline $\mathrm{DQO}\left(\mathrm{mgO}_{2} \cdot \mathrm{L}^{-1}\right)^{\star \star}$ & $9147 \pm 514$ & \\
\hline $\mathrm{OD}\left(\mathrm{mgO}_{2} \cdot \mathrm{L}^{-1}\right)$ & $2,5 \pm 0,2$ * & $\geq 5$ \\
\hline $\mathrm{OG}\left(\mathrm{mg} \cdot \mathrm{L}^{-1}\right)$ & $887 \pm 55$ * & 20 \\
\hline $\mathrm{Cr}\left(\mathrm{mg} \cdot \mathrm{L}^{-1}\right)$ & 9,940 * & 0,50 \\
\hline $\mathrm{Mn}\left(\mathrm{mg} \cdot \mathrm{L}^{-1}\right)$ & 0,570 & 1,00 \\
\hline $\mathrm{Zn}\left(\mathrm{mg} \cdot \mathrm{L}^{-1}\right)$ & 30,960 * & 5,00 \\
\hline $\mathrm{Co}\left(\mathrm{mg} \cdot \mathrm{L}^{-1}\right)$ & 0,081 * & 0,05 \\
\hline $\mathrm{Cu}\left(\mathrm{mg} \cdot \mathrm{L}^{-1}\right)$ & 0,317 & 1,00 \\
\hline $\mathrm{Ag}\left(\mathrm{mg} \cdot \mathrm{L}^{-1}\right)$ & 0,160 * & 0,10 \\
\hline As $\left(m g \cdot L^{-1}\right)$ & 0,018 & 0,50 \\
\hline $\mathrm{Pb}\left(\mathrm{mg} \cdot \mathrm{L}^{-1}\right)$ & 0,146 & 0,50 \\
\hline $\mathrm{Fe}\left(\mathrm{mg} \cdot \mathrm{L}^{-1}\right)$ & 7,850 & 15,00 \\
\hline $\mathrm{Al}\left(\mathrm{mg} \cdot \mathrm{L}^{-1}\right)$ & 43,1000 * & 0,10 \\
\hline $\mathrm{Cd}\left(\mathrm{mg} \cdot \mathrm{L}^{-1}\right)$ & 0,001 & 0,20 \\
\hline $\mathrm{Hg}\left(\mathrm{mg} \cdot \mathrm{L}^{-1}\right)$ & $<0,001$ & 0,01 \\
\hline
\end{tabular}

*: valor não-permitido pela legislação; **: limites não-estabelecidos pela legislação federal; ***: limites estabelecidos pela resolução $n=357 / 05$ do CONAMA.

de desemulsificação por acidificação do sistema de tratamento realizado pela indústria metal-mecânica, já que, nesta etapa, o efluente é acidificado para a quebra da emulsão óleo/água e, consequentemente, a retirada do óleo em excesso. Já a coloração está associada a grupos cromóforos presentes na amostra do efluente e pode ser prejudicial no descarte desse efluente no corpo receptor, aumentando o bloqueio da luminosidade, o que, consequentemente, prejudica a fotossíntese, além de dificultar a transferência de oxigênio atmosférico para o meio ambiente aquático, reduzindo, assim, o OD no meio (CETESB, 2009).

A elevada DQO $\left(9.147 \pm 514 \mathrm{mgO}_{2} \cdot \mathrm{L}^{-1}\right)$ pode ser atribuída à presença de alto teor de matéria orgânica dissolvida. Vários autores descreveram em seus trabalhos que os efluentes da indústria metal-mecânica possuem valores elevados de DQO. Cheng, Phipps e Alkhaddar (2006) determinaram uma DQO de 8.000 mg..-1 em um efluente metal-mecânico. Van Der Gast e Thompson (2004) encontraram uma DQO de aproximadamente $10.000 \mathrm{mg} . \mathrm{L}^{-1} \mathrm{em}$ uma amostra de efluente contendo fluido de corte. Monteiro (2006) caracterizou um efluente da indústria metal-mecânica semelhante ao estudado, e determinou uma DQO de aproximadamente $3.700 \mathrm{mg} . \mathrm{L}^{-1}$. Os efluentes oleosos, em geral, apresentam características altamente variáveis, sejam elas físicas, químicas ou biológicas e em seu processo de decomposição elevam a DQO, causando alterações prejudiciais aos ecossistemas aquáticos (CETESB, 2009).

A baixa concentração de $\mathrm{OD}\left(2,5 \pm 0,2 \mathrm{mgO}_{2} \cdot \mathrm{L}^{-1}\right)$ está certamente relacionada à alta $\mathrm{DQO}$, a qual, consequentemente, diminui a concentração de OD, uma característica comum de efluentes oleosos. Ekundayo e Fodeke (2000) determinaram OD de 5 mg.L-1 em um tanque receptor de vários efluentes oleosos, entre eles de indústria metal-mecânica. Já Ferreira et al. (2000) encontraram, em um efluente sem tratamento de uma refinaria de petróleo, OD inferior a $1 \mathrm{mg} . \mathrm{L}^{-1}$. Enquanto que, Conceição et al. (2005) detectaram um nível de OD maior em um efluente oleoso de refinaria, com aproximadamente $7 \mathrm{mg} \cdot \mathrm{L}^{-1}$, mostrando assim que o nível de OD é 
muito variável devido aos diferentes efluentes oleosos gerados pelas indústrias.

Neste trabalho, foi determinada uma concentração de OG de $887 \pm 55 \mathrm{mg} \cdot \mathrm{L}^{-1}$, os quais, segundo a metodologia no item 2.2.4., estão associados a substâncias solúveis em n-hexano. Estas substâncias compreendem os ácidos graxos, as gorduras animais, os sabões, as graxas, os óleos vegetais, as ceras e os óleos minerais (CETESB, 2009). Resultados semelhantes de concentração de OG em efluentes da mesma tipologia deste trabalho foram reportados na literatura. Damato, Sobrinho e Morita (1997) determinaram 871 mg.L.-1 de OG em um efluente contendo fluido de corte. Em outro trabalho, Tessaro (2008) encontrou uma concentração de até $9.942 \mathrm{mg} \cdot \mathrm{L}^{-1}$ de OG, estudando diversos efluentes metais-mecânicos. Por outro lado, Schoeman e Novhe (2007) trabalharam com um efluente semelhante, e determinaram uma concentração de $19.794 \mathrm{mg} \cdot \mathrm{L}^{-1}$.

O efluente original apresentou concentrações de cromo $(\mathrm{Cr})$, zinco (Zn), cobalto (Co), prata (Ag) e alumínio (Al) acima das permitidas pela resolução do Conama (357/05). Os efluentes da indústria metal-mecânica costumam ter altas concentrações de metais dissolvidos. Tessaro (2008) realizou o levantamento dos IM em um efluente metal-mecânico e encontrou concentrações acima daquelas permitidas pela legislação para $\mathrm{Zn}$ e $\mathrm{Al}$, cujos valores foram de 6 e 5 mg.L $L^{-1}$, respectivamente. Pereira Neto et al. (2008) determinaram altas concentrações de IM em um efluente metal-mecânico altamente ácido ( $\mathrm{pH}$ 0,6), com $92.000 \mathrm{mg} . \mathrm{L}^{-1}$ de Fe, $70.000 \mathrm{mg} . \mathrm{L}^{-1}$ de Zn, 30 mg. $L^{-1}$ de Al. Costa, Schneider e Rubio (2000), também em um efluente metal-mecânico, determinaram uma concentração de 6 mg. $L^{-1}$ de Co, 6 mg. $L^{-1}$ de Zn e 4 mg. $L^{-1}$ de Fe. Desta maneira, pode-se observar que a concentração específica de cada metal nos efluentes metais-mecânicos pode ter uma grande variação, e está associada com os processos de usinagem utilizados por cada indústria.

\section{Tratamento por precipitação química para a remoção dos IM}

O principal objetivo deste tratamento foi a retirada de possíveis IM presentes na amostra do efluente metal-mecânico. Além de propiciar a redução de outros parâmetros, como matéria orgânica, do efluente bruto.

$\mathrm{Na}$ usinagem, processo utilizado pelas indústrias metais-mecânicas, que tem como objetivo conferir à peça metálica sua forma final, é produzido o cavaco. O cavaco é a porção de material metálico removido da peça original. Por esse motivo, o efluente final é composto, entre outros constituintes, por concentrações elevadas de metais providos dos cavacos (OLIVEIRA, 2005). Os metais comumente encontrados neste tipo de efluente são: zinco, cádmio, manganês, chumbo, entre outros (FUNGARO et al., 2005; NASCIMENTO et al., 2006).
Os IM do efluente foram determinados com o mesmo na sua forma original ( $\mathrm{pH} 1,7)$ e com seis diferentes $\mathrm{pHs}$ ajustados. Os pHs foram 6,$5 ; 7,5 ; 8,5 ; 9,5 ; 10,5$ e 11,5. Após os ajustes de pHs, as amostras foram deixadas em repouso por três horas para total decantação de materiais sedimentáveis, entre eles os IM, e, em seguida, coletou-se a fase aquosa para a determinação dos metais presentes na mesma. Os resultados referentes a esta metodologia são apresentados na Tabela 2.

Quando o pH do efluente foi ajustado para 7,5, todos os metais presentes em sua fase aquosa apresentaram concentrações permitidas pela legislação.

Os metais podem ser precipitados na forma de hidróxidos, sulfetos e complexos orgânicos. Porém, quando há excesso do agente precipitante, como, por exemplo, $\mathrm{NaOH}$, pode haver o aumento da solubilidade do metal. Isso ocorre devido à formação de íons complexos, os quais podem se ligar com outros íons de carga oposta ou com moléculas de água (VOGUEL, 1981). Isso possivelmente explica a resolubilidade de alguns metais e, consequentemente, a determinação dos mesmos em concentrações mais elevadas quando os pHs foram superiores à 7,5 .

Pereira Neto et al. (2008) ajustaram o pH de um efluente metalmecânico, altamente ácido, para diferentes valores, e conseguiram remover de forma satisfatória os metais Fe, Zn, Al, Ni e Cu. Esses autores obtiveram concentrações permitidas pela legislação (resolução CONAMA n $357 / 05$ ) de todos os metais estudados em valores de $\mathrm{pH}$ superiores a 7,0. Entretanto, Bresaola Jr. e Carrara (2000) ajustaram o pH de um efluente da indústria metal-mecânica entre 7 a 11, e conseguiram uma remoção acima de 90\% dos IM, Fe e Zn, em pH 8 e com tempo de sedimentação de 1,5 hora.

\section{Biotratamento em reator do tipo air-lift}

O biotratamento do efluente, pré-tratado por precipitação química ( $\mathrm{pH} 7,5)$, ocorreu com os microorganismos autóctones do próprio efluente (FI e FV) e o micro-organismo, utilizado como referência, A. niger, já que vários trabalhos sobre efluentes oleosos o utilizam para seu tratamento. Os resultados referentes a esse tratamento estão expostos na Tabela 3.

Após o tratamento integrado, observou-se que o pH aumentou em média $11 \pm 1 \%$ após o tratamento. Este aumento pode estar associado à decomposição de ácidos graxos, presentes na amostra, pela ação enzimática dos fungos (MENDES et al., 2005).

A redução de cor foi semelhante para os três fungos, sendo sempre acima de $90 \%$. Utilizando o fungo FV, a redução foi de $95 \pm 1 \%$, enquanto que, para FI e A. niger, foi de $92 \pm 1 \%$. Indicando, desta maneira, que tanto a ação enzimática como uma possível adsorção dos grupos cromóforos foram eficazes para sua redução no efluente.

A redução da DQO foi mais significativa quando o efluente foi tratado com o micro-organismo FI, chegando a $52 \pm 2 \%$. Já utilizando o fungo de referência $A$. niger, essa redução foi semelhante, alcançando $49 \pm 2 \%$. Van Der Merwe, Badenhorst e Britz (2005) estudaram o 
Tabela 2 - Concentração de IM no efluente bruto com pH 1,7 e ajustado para os pHs 6,5; 7,5; 8,5; 9,5; 10,5 e 11,5.

\begin{tabular}{|c|c|c|c|c|c|c|c|}
\hline \multirow{2}{*}{ Metal (mg. $\left.\mathrm{L}^{-1}\right)$} & \multicolumn{7}{|c|}{$\mathrm{pH}$} \\
\hline & 1,7 & 6,5 & $7,5 * *$ & 8,5 & 9,5 & 10,5 & 11,5 \\
\hline $\mathrm{Cr}$ & $9,940 *$ & 0,070 & 0,045 & 0,497 & 0,130 & 0,093 & 0,296 \\
\hline $\mathrm{Mn}$ & 0,570 & 0,514 & 0,465 & 0,234 & 0,109 & 0,132 & 0,220 \\
\hline $\mathrm{Zn}$ & $30,960^{\star}$ & $14,490^{\star}$ & 2,280 & 3,260 & 1,100 & 1,990 & $9,300^{*}$ \\
\hline Co & $0,081^{*}$ & 0,037 & 0,029 & $0,061^{*}$ & $0,076^{\star}$ & $0,055^{\star}$ & 0,031 \\
\hline $\mathrm{Cu}$ & 0,317 & 0,078 & 0,093 & 0,051 & 0,137 & 0,166 & 0,206 \\
\hline $\mathrm{Ag}$ & $0,160^{\star}$ & 0,100 & 0,100 & 0,100 & $0,111^{\star}$ & $0,153^{*}$ & $0,160^{*}$ \\
\hline As & 0,018 & 0,014 & 0,008 & 0,013 & 0,008 & 0,003 & 0,012 \\
\hline $\mathrm{Pb}$ & 0,146 & 0,003 & 0,006 & 0,008 & 0,005 & 0,005 & 0,006 \\
\hline $\mathrm{Fe}$ & 7,850 & $<0,011$ & 0,551 & 2,959 & 3,784 & 7,017 & 7,260 \\
\hline $\mathrm{Al}$ & $43,100^{*}$ & $0,860^{*}$ & $<0,010$ & $4,060^{*}$ & $5,030^{*}$ & $18,810^{*}$ & 26,230 * \\
\hline $\mathrm{Cd}$ & 0,0008 & $<0,0001$ & 0,0002 & 0,0001 & 0,0006 & 0,0004 & 0,0004 \\
\hline $\mathrm{Hg}$ & $<0,001$ & $<0,001$ & $<0,001$ & $<0,001$ & $<0,001$ & $<0,001$ & $<0,001$ \\
\hline
\end{tabular}

*: valor acima do permitido pela resolução no 357/05 do Conama; **: pH em que o efluente se apresentou com todos os metais determinados em concentrações aceitáveis.

Tabela 3 - Reduções totais dos parâmetros avaliados após o tratamento integrado por precipitação química e biotratamento utilizando os microorganismos $A$. niger, Fl e FV

\begin{tabular}{|c|c|c|c|c|c|c|}
\hline \multirow{3}{*}{$\begin{array}{l}\text { Parâmetros } \\
\text { pós-tratamento }\end{array}$} & \multicolumn{6}{|c|}{$\begin{array}{l}\text { Sistema integrado } \\
\text { (Precipitação química e biotratamento) }\end{array}$} \\
\hline & \multicolumn{2}{|c|}{ A. niger } & \multicolumn{2}{|c|}{$\mathrm{FI}$} & \multicolumn{2}{|c|}{ FV } \\
\hline & Valor & $\begin{array}{l}\text { Redução } \\
\text { total (\%) }\end{array}$ & Valor & $\begin{array}{l}\text { Redução } \\
\text { total (\%) }\end{array}$ & Valor & $\begin{array}{l}\text { Redução } \\
\text { total (\%) }\end{array}$ \\
\hline $\mathrm{pH}$ & $7,3 \pm 0,1$ & $12 \pm 1^{*}$ & $7,3 \pm 0,1$ & $12 \pm 1^{*}$ & $6,9 \pm 0,1$ & $6 \pm 1^{*}$ \\
\hline Cor & $117 \pm 5$ & $92 \pm 1$ & $117 \pm 5$ & $92 \pm 1$ & $71 \pm 3$ & $95 \pm 1$ \\
\hline DQO & $4701 \pm 150$ & $49 \pm 2$ & $4397 \pm 175$ & $52 \pm 2$ & $5442 \pm 140$ & $41 \pm 2$ \\
\hline OD & $8,0 \pm 0,2$ & $220 \pm 8^{*}$ & $7,8 \pm 0,3$ & $212 \pm 12^{*}$ & $7,6 \pm 0,1$ & $204 \pm 4^{*}$ \\
\hline$O G$ & $530 \pm 15$ & $40 \pm 1$ & $340 \pm 10$ & $62 \pm 1$ & $405 \pm 15$ & $54 \pm 1$ \\
\hline
\end{tabular}

*: aumento percentual.

tratamento biológico de um efluente oleoso, com $\mathrm{pH}$ próximo à 5,5 e temperatura de $30^{\circ} \mathrm{C}$. Porém, esses autores inocularam o efluente com um consórsio fúngico, e conseguiram uma redução máxima de $51 \%$ da DQO.

Em todos os tratamentos, observou-se aumento na concentração de OD do efluente. O tratamento realizado com $A$. niger foi o que obteve o aumento mais significativo de oxigênio, sendo de $220 \pm$ $8 \%$. Quando o tratamento foi realizado com os fungos FI e FV, o OD do efluente aumentou em $212 \pm 12 \%$ e $204 \pm 4 \%$, respectivamente. Porém, boa parte deste aumento pode ser atribuído ao oxigênio adicionado ao reator para o funcionamento do mesmo.

Os tratamentos realizados com os micro-organismos autóctones do efluente também foram mas eficazes na redução de $O G$, do que o tratamento que utilizou o fungo de referência A. niger. Utilizando FI e FV, as reduções efetivas foram de $62 \pm 1 \%$ e $54 \pm 1 \%$, respectivamente. Já com o fungo A. niger, a redução foi de $40 \pm 1 \%$. A redução de OG pode ter ocorrido pela ação de diversas enzimas, entre elas as lípases, que são comuns em micro-organismos isolados de meios oleosos, como os estudados no presente trabalho (BHUMIBHAMON; KOPRASERTSAK; FUNTHONG, 2002).
Tano-Debrah et al. (1999) trataram uma amostra de efluente oleoso durante sete dias, a $30^{\circ} \mathrm{C}$ e pH 7 , com a inoculação de $5 \times 10^{8}$ esporos/mL de diferentes micro-organismos (sem identificação) e obtiveram $86 \%$ de degradação de OG, aumentando o OD da amostra em $30 \%$ e diminuindo sua DQO em $60 \%$.

\section{Conclusões}

Os objetivos deste trabalho foram realizar a caracterização físicoquímica de um efluente metal-mecânico e efetuar o tratamento integrado (precipitação química e biotratamento), utilizando micro-organismos autóctones do efluente (FI e FV) e uma referência (A. niger).

A caracterização do efluente oleoso bruto mostrou que, em decorrência dos parâmetros determinados, como pH (1,7), DQO (9147 $\left.\mathrm{mgO}_{2} \cdot \mathrm{L}^{-1}\right)$ e OG (887 mg. $\left.\mathrm{L}^{-1}\right)$, o mesmo possui um alto potencial poluidor.

Com o tratamento por precipitação química, foram obtidas, em pH 7,5, a sedimentação e remoção satisfatória de todos os IM investigados. Neste $\mathrm{pH}$, os mesmos indicaram concentrações permitidas pela legislação (resolução n³57/05 - Conama). 
O biotratamento em reator air-lift, após a precipitação química, reduziu todos os parâmetros determinados, exceto o pH, que aumentou em média 11\%. O microorganismo FV se mostrou mais eficaz na redução de cor (95\%). Enquanto que FI foi mais eficaz na redução da DQO (52 \%) e OG (62 \%), o que indica que os micro-organismos autóctones do efluente (FI e FV) foram mais eficazes no tratamento do que o padrão A. niger, tratando-se de microorganismos com alto potencial de remediação neste tipo de efluente.

\section{Referências}

APHA. Standard methods for examination of water and wastewater. Washington DC: American Public Health Association, 1998. 20 ed.

BHUMIBHAMON, O.; KOPRASERTSAK, A.; FUNTHONG, S. Biotreatment of High Fat and Oil Wastewater by Lipase Producing Microorganisms, Kasetsart Journal (Natural Science), v. 36, p. 261-267, 2002.

BIO-WISE. A Guide to Biological Treatment for Metalworking Fluids Disposal. London: Department of Trade and Industry, 2000.

BRESAOLA JR., R.; CARRARA, S.M.C.M. Reuso de Águas Residuárias Geradas em Processos de Galvanoplastia. Rio de Janeiro: Associação Brasileira de Engenharia Sanitária - ABES, 2000. p. 1-6.

CPPA. Technical Section Standard Method H5P. Color of Pulp Mill Effluents. Canada: Canadian Pulp and Paper Association, 1975.

COMPANHIADETECNOLOGIADESANEAMENTO AMBIENTAL (CETESB). Significado ambiental e sanitário das variáveis de qualidade das águas e dos sedimentos e metodologias analíticas e de amostragem. Disponível em: <http://www.cetesb.sp.gov.br>. Acesso em: 27 fev. 2009.

CHENG, C.; PHIPPS, D.; ALKHADDAR, R.M. Thermophilic aerobic wastewater treatment of waste metalworking fluids, Water and Environment Journal, v. 20, p. 227-232, 2006.

Treatment of spent metalworking fluids, Water Research, v. 39, p. 4051-4063, 2005.

CONSELHO NACIONAL DO MEIO AMBIENTE (CONAMA). Resolução $n^{\circ}$ 357, 17 março 2005. Disponível em: <http://www.mma.gov.br>. Acesso em: 21 jul. 2009.

CONCEIÇÃO, D.M.; DE ANGELIS, D.A.; BIDOIA, E.D.; DE ANGELIS, D. F. Fungos Filamentosos Isolados do Rio Atibaia, SP e Refinaria de Petróleo Biodegradadores de Compostos Fenólicos, Arquivos do Instituto Biológico. v. 72, p. 99-106, 2005.

COSTA, C.A.; SCHNEIDER, I.A.H.; RUBIO, J. Plantas aquáticas secas: Uma alternativa moderna para remoção de metais pesados em efluentes industriais, Engenharia Sanitária Ambiental, v. 5, p. 19-24, 2000.

DAMATO, M.; SOBRINHO, P.A.; MORITA, D.M. Determinação da toxicidade aguda de efluentes de refinaria de petróleo em diversas etapas de tratamento para Dapnia similis. In: CONGRESSO BRASILEIRO DE ENGENHARIA SANITÁRIA E AMBIENTAL, setembro 14-19, 1997. Foz do Iguaçu: Associação Brasileira de Engenharia Sanitária e Ambiental, 1997. p. 119.

EKUNDAYO, E.O.; FODEKE, V.O. Microbial densities and physicochemical quality of some crude oil flowstations' Saver pit effluents in the niger delta basin of Southern Nigeria, Environmental Monitoring and Assessment, v. 65, p. 523-530, 2000.

FERREIRA, E.F.T.; ALMEIDA, J.H.C.; SANTIAGO, V.M.J.; WACHBURGER, R.L. Aplicação da estação de tratamento de despejos industriais (EDTI) da refinaria Alberto Pasqualini (REFAP) da Petrobras. In: XXVII CONGRESSO INTERAMERICANO DE ENGENHARIA SANITÁRIA E AMBIENTAL, Fortaleza-CE, 2000.

FUNGARO, D.A.; IZIDORO, J.C.; ALMEIDA, R.S. Remoção de compostos tóxicos de solução aquosa por adsorção com zeólita sintetizada a partir de cinzas de carvão, Eclética Química, v. 30, p. 31-35, 2005.

KURNIAWAN, T.A.; CHAN G.Y.S.; WAI-HUNG LO; BABEL, S. Physicochemical treatment techniques for wastewater laden with heavy metals, Chemical Engineering Journal, v. 118, p. 83-98, 2006.

LEMOS, J.L.S.; SANTOS, R.L.C. Aplicação de microrganismos na recuperação de metais. Centro de Tecnologia Mineral (CETEM). Série Anais. Rio de Janeiro: Ed. CETEM, 2007, 446 p.

MATLOCK, M.M.; HOWERTON B.S.; ATWOOD, D.A. Chemical precipitation of heavy metals from acid mine drainage, Water Research, v. 36, p. 4757-4764, 2002.

MENDES, A.A.; CASTRO, H.F.; PEREIRA, E.B.; FURIGO JR., A. Aplicação de lipases no tratamento de águas residuárias com elevados teores de lipídeos, Química Nova, v. 28, p. 296-305, 2005.

MONTEIRO, M. I. Tratamento de Efluentes Oleosos Provenientes da Indústria Metal-Mecânica e seu Reuso. Tese (Doutorado) - Universidade de São Paulo, Escola de Engenharia de Lorena, p.148, 2006.

NASCIMENTO, S.C.; HYPOLITO, R.; RIBEIRO, A.A. Disponibilidade de metais pesados em aterro de indústria siderúrgica, Engenharia Sanitária Ambiental, v. 11, p. 196-202, 2006

OLIVEIRA, A. Otimização das condições de usinagem visando o torneamento a seco do aço ABNT 1045 em operação de desbaste. p. 115. Dissertação (Mestrado) - Universidade de Campinas, Campinas, 2005

PEREIRA NETO, A.; BRETZ, J.S.; MAGALHÃES, F.S.; MANSUR, M.B.; ROCHA, S.D. F. Alternativas para o tratamento de efluentes da indústria galvânica, Revista Engenharia Sanitária Ambiental, v. 13, p. 263-270, 2008

ROSSMOORE H.W. Biostatic Fluids, Friendly Bacteria and Other Myths in Metalworking Microbiology, Lubrication Engineering, v. 49, p. 253-260, 1993 
SCHOEMAN, J. J.; NOVHE O. Evaluation of microfiltration for the treatment of spent cutting-oil, Water SA, v. 33, p. 245-248, 2007.

TANO-DEBRAH, K.; FUKUYAMA, S.; OTONARI, N.; TANIGUCHI, F.; OGURA, M. An inoculum for the aerobic treatment of wastewaters with high concentrations of fats and oils, Bioresource Technology, v. 69, p. 133-139, 1999

TESSARO, E. P. Avaliação de processos oxidativos para o tratamento ambiental adequado de fluidos de corte. Dissertação (Mestrado) Universidade de São Paulo, p. 96, 2008.

VAN DER GAST, C.J.; KNOWLES, C.J.; STARKEY, M.; THOMPSON, I.P. Selection of microbial consortia for treating metal-working fluids, Journal of Industrial Microbiology \& Biotechnology, v. 29, p. 20-27, 2002
VAN DER GAST, C.J.; THOMPSON, I.P. Effects of ph amendment on metal working fluid wastewater biological treatment using a defined bacterial consortium, Biotechnology and Bioengineering, v. 89, p. 357366,2004

VAN DER MERWE, R.; BADENHORST, J.; BRITZ, T.J. Fungal treatment of an edible oil containing industrial effluent, Word Journal of Microbiology and Biotechnology, v. 21, p. 947-953, 2005

VOGUEL, A.L. Análise Inorgânica Quantitativa. 4 ed. Rio de Janeiro: Ed Guanabara Dois, 1981. 692 p.

ZHOU, P.; HUANG, J.; LI, A. W. F.; WEI, S. Heavy metal removal from wastewater in fluidized bed reactor, Water Research, v. 33, p. 1918-1924, 1999 